Article

\title{
Tissue-Like Phantoms as a Platform for Inserted Fluorescence Nano-Probes
}

\author{
Tsviya Nayhoz, Eran A. Barnoy and Dror Fixler* \\ Faculty of Engineering and the Institute of Nanotechnology and Advanced Materials, Bar Ilan University, \\ Ramat Gan 5290002, Israel; tsviya@gmail.com (T.N.); eabnoy@gmail.com (E.A.B.) \\ * Correspondence: Dror.Fixler@biu.ac.il; Tel.: +972-3-531-7598
}

Academic Editor: Zeev Zalevsky

Received: 19 September 2016; Accepted: 9 November 2016; Published: 15 November 2016

\begin{abstract}
Tissue-like phantoms are widely used as a model for mimicking the optical properties of live tissue. This paper presents the results of a diffusion reflection method and fluorescence lifetime imaging microscopy measurements of fluorescein-conjugated gold nanorods in solution, as well as inserted in solid tissue-imitating phantoms. A lack of consistency between the fluorescence lifetime results of the solutions and the phantoms raises a question about the ability of tissue-like phantoms to maintain the optical properties of inserted contrast agents.
\end{abstract}

Keywords: tissue-like phantoms; dual-modal imaging; fluorescence lifetime (FLT); FLT imaging (FLIM); diffusion reflection

\section{Introduction}

Tissue-like phantoms play a vital role in the development and validation of new imaging technologies. Live tissue features can be replicated by phantoms through control over their optical properties [1-3]. Phantoms have been designed to replicate the optical properties of a range of tissues for optical applications such as optical coherence tomography (OCT) [1], magnetic resonance imaging [4], and diffusion reflection (DR) [5]. Such phantoms are a key requirement for the continued development of biomedical techniques and applications. For example: Cubeddu et al. showed the relations, within a phantom, between the concentration of Intralipid (IL) as a scattering component and India ink as an absorbing component to the scattering and absorption coefficients of the phantom, respectively [3]. Early phantoms were based on hydrogels, of which two of the most common were agar [6] and gelatin [7]. Today, other materials are known for the development of versatile tissue-simulating phantoms like: silicone [8], poly(vinyl alcohol) cryogels [9], and fibrin [10]. Phantoms are widely used for a number of purposes including: initial tests of novel systems, routine quality control measurements, performance comparison of different systems, and signal to noise ratio (SNR) optimization in existing systems [1]. This paper presents the initial results of fluorescence lifetime imaging microscopy (FLIM) and DR dual-modal imaging using fluorescein-conjugated-gold nanorods (GNRs), in both solutions and tissue-imitating phantoms. These results, however, raise a question of whether tissue-like phantoms maintain the optical properties of inserted contrast agents.

Biological imaging can be done by a large variety of tools that can image biological tissues. Some of the most frequently used methods are OCT [11], transmission electron microscopy (TEM) [12] and thermal imaging [13]. Biological imaging applications for biomolecular research and diagnostics are endless. One of the challenges in the field of biological imaging is to maximize the information obtained from an image. A way to do it is to combine different methods, a process known as multi-modal imaging. Each imaging method has a set of parameters it extracts, which is different for every method. Moreover, this set of parameters is characterized by factors such as spatial resolution, temporal resolution, detection sensitivity, tissue penetration, SNR, quantitative accuracy, and more [14]. By using 
more than one imaging technique the advantages of one method can compensate for the drawbacks of the other. This way it is possible to acquire as informative a picture as possible for a specific area [15-17].

However, different imaging methods require different contrast agents and it is problematic to simply add two different classes of imaging probes without the same pharmacodynamic properties [18]. Moreover, multiple doses of contrast agents can add stress on the body's blood clearance mechanism [19]. Therefore, multifunctional integrated contrast agents or probes for multi-modal imaging have been developed to solve this problem. Various methods have been applied to achieve multimodal functionality in a single probe unit. Some of them are: lipid-based approaches that use lipid carrier systems as vehicles [20-24], macromolecular carriers that form multifunctional probes by coupling different types of contrast agents to a common macromolecule $[19,25,26]$, small molecule multimodal probes [19], and organic and inorganic nanoparticles that are fabricated or modified into multifunctional probes by conjugation to molecules, load encapsulation using a core and/or shell, or doping with various materials [19].

A dual-modal imaging technique that combines FLIM and DR using fluorophore-conjugated gold nano-particles (GNPs) has been presented recently by our research group $[27,28]$. However, the aspect of the separation distance between the GNPs and fluorophores had not been explored in such easy-to-manufacture and simple probes. Metallic nanostructures have a strong interaction with incident light, which results in the generation of surface plasmons (SPs) in the metal. Excited fluorophores (as dipoles) within a short distance of the metal (less than $50 \mathrm{~nm}$ ) interact strongly with those SPs [29]. This interaction results in FLT shortening and increased (metal enhanced fluorescence) $[30,31]$ or decreased [32] quantum yield. The interaction is distance and dipole orientation dependent [33-35]. In the experiment presented here, fluorescein-conjugated-GNRs with different conjugation distances have been fabricated and examined to optimize the nano-probes. DR measurements of fluorescein-conjugated-GNR phantoms were performed, as well as time-domain FLIM measurements of fluorescein-conjugated-GNRs, both in solution and inserted in tissue-like phantoms. Although the DR measurements behaved as hypothesized, the FLIM results revealed that there was no consistent relationship between the FLT measurements of the solutions and the phantoms with the same nano-probes. This discrepancy leads us to assume that the tissue-like phantoms do not maintain the optical properties of their inserted contrast agents.

\section{Results}

In order to examine the DR system's ability to detect the fluorescein-conjugated-GNR nano-probes and their concentration, 12 solid phantoms that contain fluorescein-conjugated-GNRs were made as described in the Materials and Methods section: six with conjugation through 11-amino-1-undecanethiol linker and six with conjugation through 6-amino-1-hexanethiol linker. The Au concentration of each set of six phantoms varied from $0.05 \mathrm{mg} / \mathrm{mL}$ to $0.3 \mathrm{mg} / \mathrm{mL}$ by steps of $0.05 \mathrm{mg} / \mathrm{mL}$. In addition, control phantoms containing fluorescein with matching fluorescein concentrations were made as well.

DR measurements of the phantoms described above were performed. The reflected light intensity from the different solid phantoms was measured using a DR set-up with laser sources of 650 and $780 \mathrm{~nm}$ as described in the Materials and Methods section. The slope of $\ln \left(\varrho^{2} \Gamma(\varrho)\right)$ was calculated, where $\Gamma(\varrho)$ describes the reflected light intensity at the phantom surface in several light source-detector separations (represented by $\varrho$ ). Figure 1 shows a bar plot of the $\ln \left(\varrho^{2} \Gamma(\varrho)\right.$ ) slopes of the fluorescein-conjugated-GNR phantoms with different GNR concentrations and the control phantom with matching dye concentrations. 


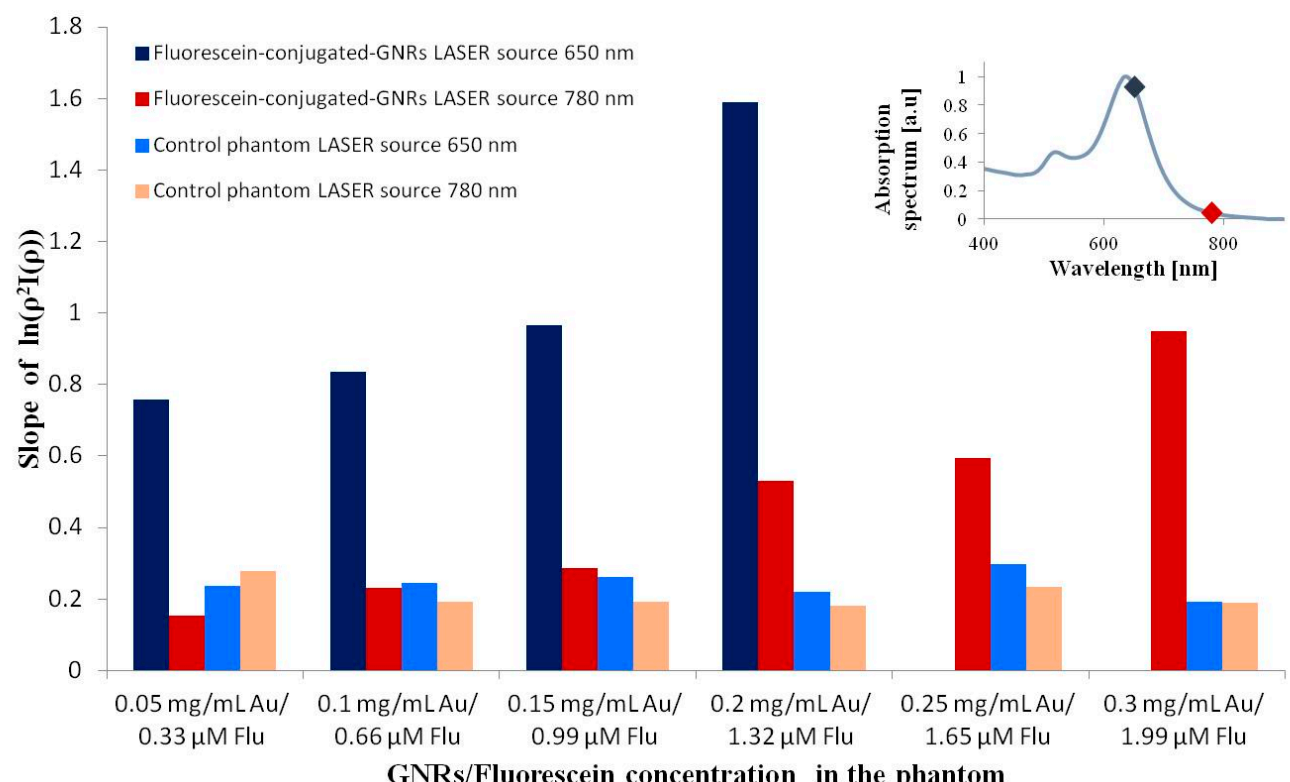

Figure 1. A bar plot of $\ln \left(\varrho^{2} \Gamma(\varrho)\right)$ slopes of the different phantoms, which were measured using the DR method. In the upper right corner, the absorption spectrum of the GNRs is presented with the DR light source wavelengths marked by diamonds.

Solutions and tissue-like phantoms with fluorescein, each with a fluorescein concentration of $0.33 \mu \mathrm{M}$, were made. Fluorescein was conjugated to GNRs using linkers of varying lengths, and also prepared in solutions and phantoms. These solutions had a fluorescein concentration of $6.6 \mu \mathrm{M}$, and the phantoms had a concentration of $0.33 \mu \mathrm{M}$. All samples were measured using the time-domain FLIM system. The system's excitation rate was $50 \mathrm{MHz}$, the pinhole diameter $2 \mathrm{~mm}$ and the sample was scanned to an image with a varied number of pixels up to a maximum of $64 \times 64$ pixels.

The fluorescence intensity (FI) decay of each pixel of the fluorescein solution sample was fitted to a mono-exponential curve. An average over all of the pixels yielded a FLT of $3.92 \pm 0.04 \mathrm{~ns}$ (Figure 2 shows a histogram of $\tau_{1}$ for the fluorescein solution measurement). The FI decay of each pixel of the fluorescein-conjugated-GNR solutions was fitted to a bi-exponential function where $\tau_{2}$ was fixed to $3.92 \mathrm{~ns}$ (the FLT measured for free fluorescein solution). The average values and STD of $\tau_{1}, \mathrm{a}_{1} \%$ (the percentage of $\tau_{1}$ of the pixel's FLT), and $\chi^{2}$ (the fit quality parameter), were calculated and are summarized in Table 1, and Figure 3 presents the $\tau_{1}$ histograms for the fluorescein-conjugated-GNR solutions.

Table 1. This table summarizes the results of $\tau_{1}, a_{1} \%$ (the percentage of $\tau_{1}$ of the pixel's FLT), $\chi^{2}$ (the fit quality parameter) average, and the standard deviation (STD) values for fluorescein-conjugated GNRs with different linkers.

\begin{tabular}{|c|c|c|c|c|c|c|c|}
\hline Linker Type & $\begin{array}{l}\text { Estimated Linker } \\
\text { Length }[\mathrm{nm}]\end{array}$ & $\begin{array}{l}a_{1} \%- \\
\text { Average }\end{array}$ & $\begin{array}{l}a_{1} \%- \\
\text { STD }\end{array}$ & $\underset{[\mathrm{ns}]}{\tau_{1} \text {-Average }}$ & $\begin{array}{c}\tau_{1}-\mathrm{STD} \\
{[\mathrm{ns}]}\end{array}$ & $\begin{array}{c}\chi^{2}- \\
\text { Average }\end{array}$ & $\begin{array}{l}\chi^{2}- \\
\text { STD }\end{array}$ \\
\hline NH2-PEG-SH-5 kDa & 50 & 81.16 & 6.13 & 1.15 & 0.24 & 1.312 & 0.535 \\
\hline NH2-PEG-SH-1 kDa & 10 & 91.15 & 6.52 & 0.74 & 0.23 & 1.461 & 0.327 \\
\hline 16-amino-1-hexadecanethiol & 2.5 & 87.02 & 3.55 & 1.95 & 0.13 & 1.609 & 0.149 \\
\hline 11-amino-1-undecanethiol & 1.7 & 66.13 & 13.49 & 2.72 & 0.28 & 1.366 & 0.332 \\
\hline 6-amino-1-hexanethiol & 0.9 & 81.03 & 6.46 & 1.10 & 0.17 & 1.259 & 0.360 \\
\hline $\begin{array}{c}\text { 3,4-methylenedioxy- } N, N- \\
\text { dimethylamphetamine } \\
\text { (MDDA) }\end{array}$ & Unkown & 80.84 & 6.84 & 2.38 & 0.18 & 1.124 & 0.132 \\
\hline
\end{tabular}




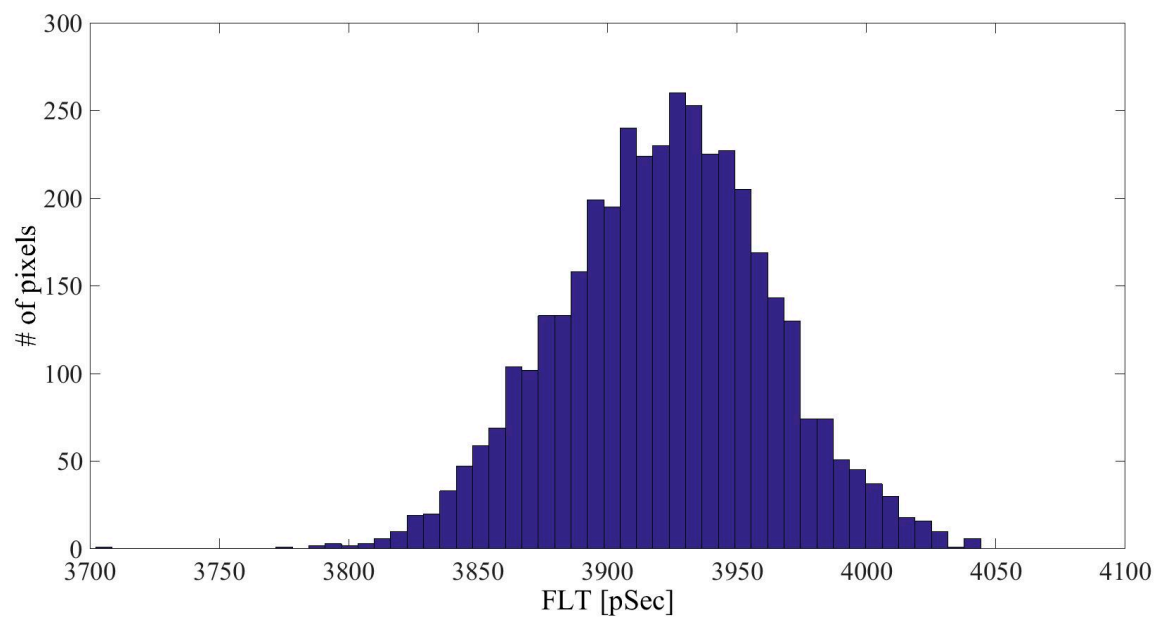

Figure 2. FLT histogram of fluorescein $0.33 \mu \mathrm{M}$ solution.

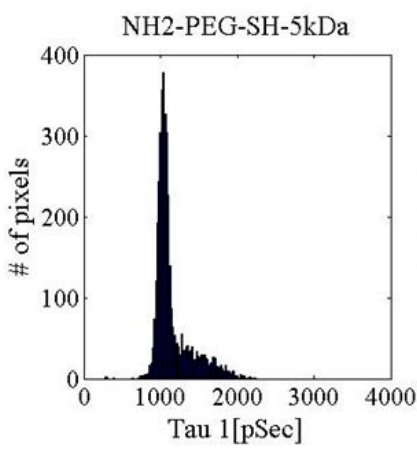

(a)

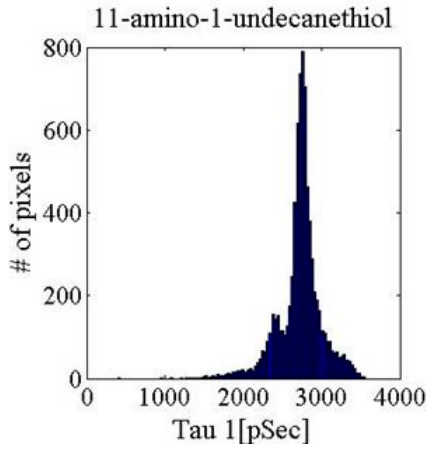

(d)

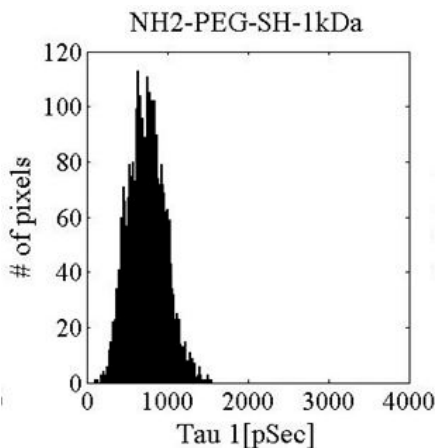

(b)

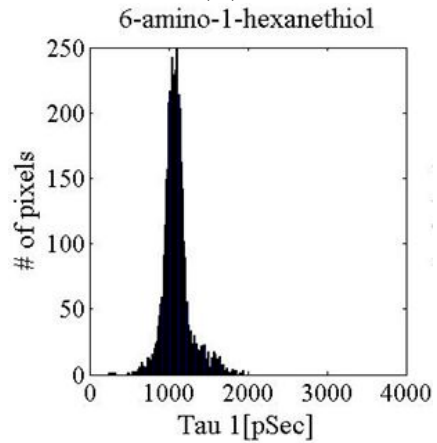

(e)

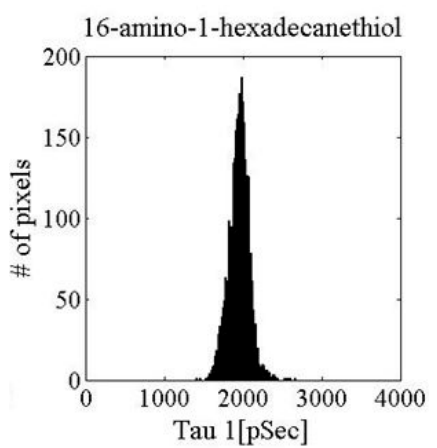

(c)

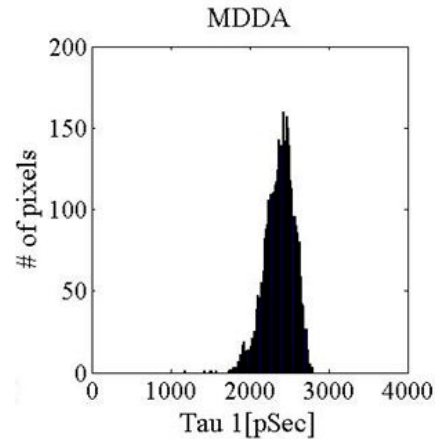

(f)

Figure 3. $\tau_{1}$ histograms for fluorescein-conjugated GNR solutions with different linkers: (a) $\mathrm{NH}_{2}$-PEG-SH-5 kDa; (b) $\mathrm{NH}_{2}$-PEG-SH-1 kDa; (c) 16-amino-1-hexadecanethiol; (d) 11-amino-1-undecanethiol; (e) 6-amino-1-hexanethiol; (f) MDDA (Au concentration $1 \mathrm{mg} / \mathrm{mL}$, fluorescein concentration $6.6 \mu \mathrm{M})$.

The FI decay of each pixel of the free fluorescein phantom was fit to a mono-exponential curve. An average over all of the pixels yielded a FLT of $3.74 \pm 0.06 \mathrm{~ns}$. Figure 4 shows a histogram of $\tau_{1}$ for the fluorescein phantom measurement. The fluorescein-conjugated-GNR phantoms were measured at three different areas. The FI decay of each pixel of the fluorescein-conjugated-GNR phantom images was fit to a bi-exponential function where $\tau_{2}$ was fixed to 3.74 ns (the FLT measured for the free fluorescein phantom). The average values and STD of $\tau_{1}, a_{1} \%$ (the percentage of $\tau_{1}$ of the pixel's FLT), and $\chi^{2}$ (the fit quality parameter), were calculated and are summarized in Table 2 , and the corresponding $\tau_{1}$ histograms are presented in Figure 5. 


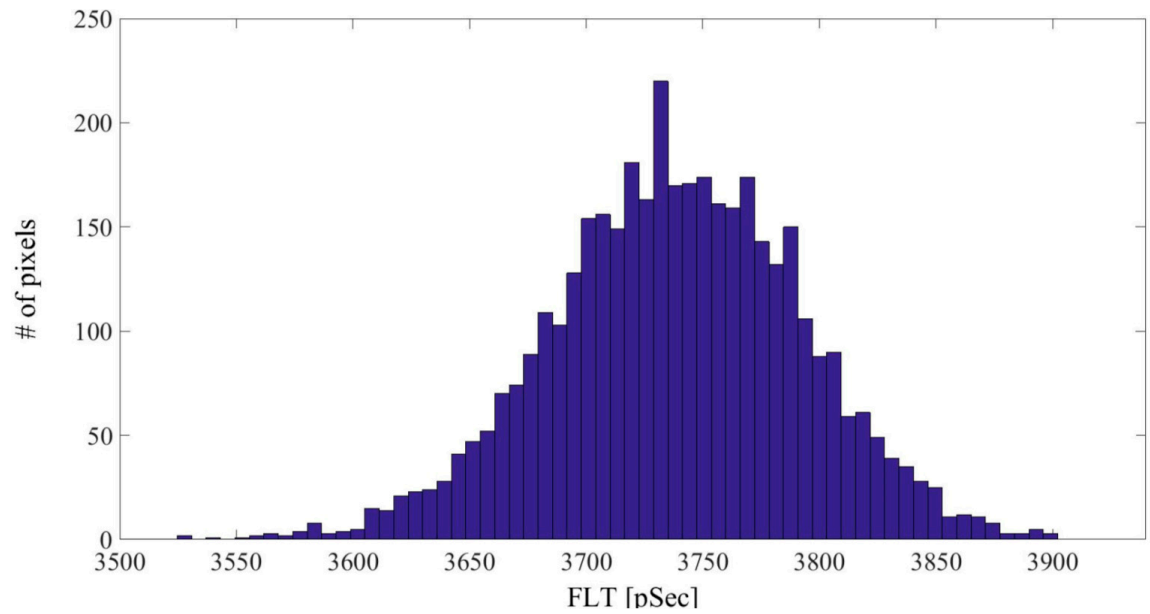

Figure 4. FLT histogram of free fluorescein phantom. The fluorescein concentration in the phantom was $0.33 \mu \mathrm{M}$.

Table 2. This table summarizes the results of $\tau_{1}, a_{1} \%$ (the percentage of $\tau_{1}$ of the pixel's FLT), $\chi^{2}$ (the fit quality parameter average), and standard deviation (STD) values for fluorescein-conjugated GNRs with different linkers. Each phantom was measured in three areas, marked as (1), (2), and (3) for each phantom. In all phantoms, Au concentration was $0.05 \mathrm{mg} / \mathrm{mL}$ and fluorescein concentration was $0.33 \mu \mathrm{M}$.

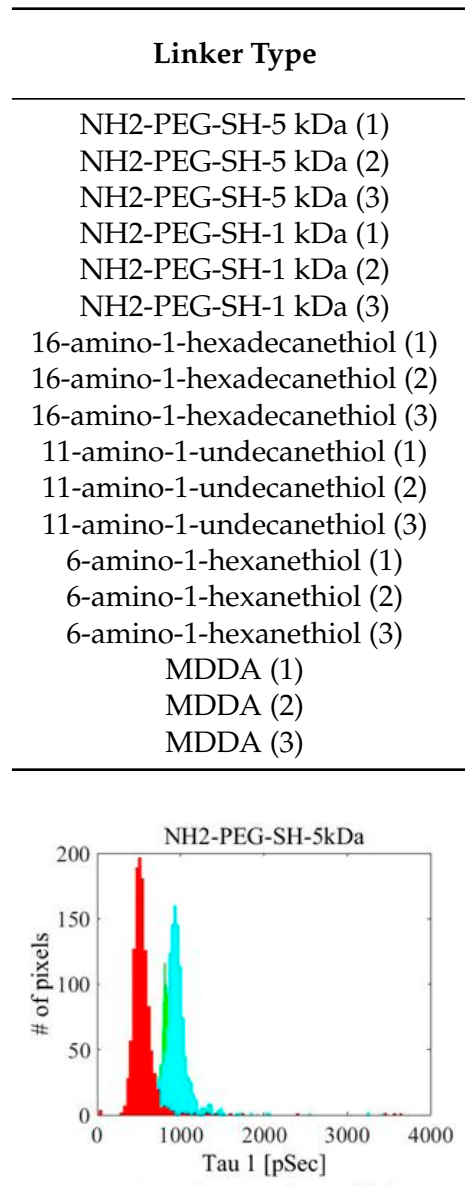

(a)

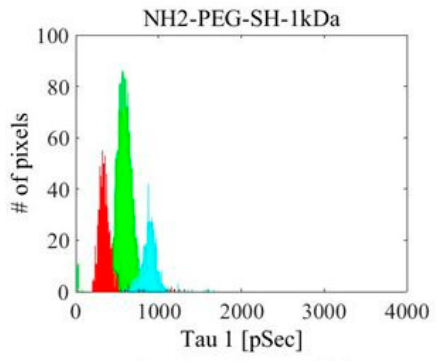

(b)

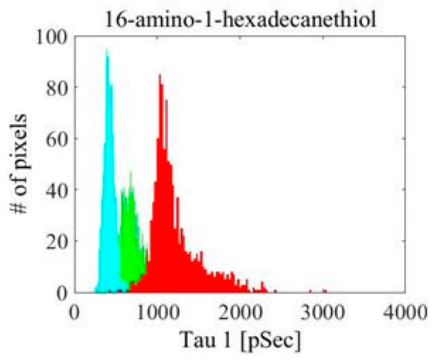

(c)

Figure 5. Cont. 


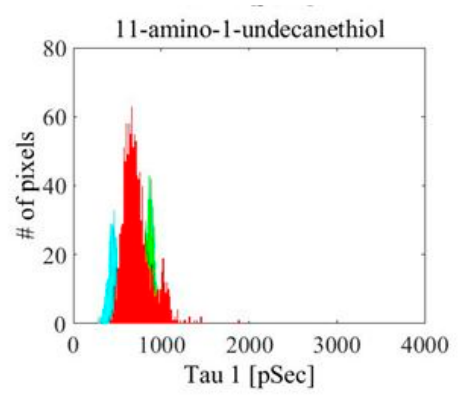

(d)

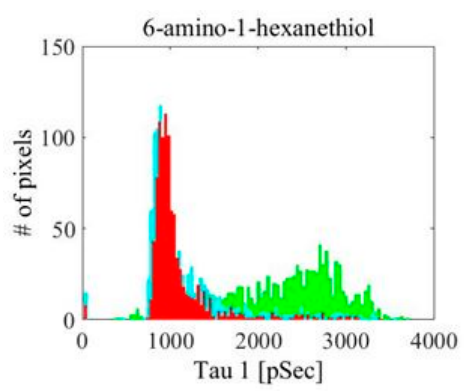

(e)

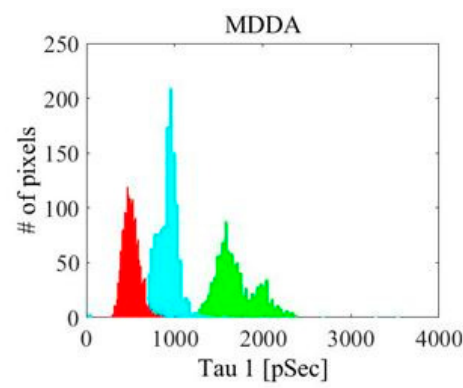

$(\mathbf{f})$

Figure 5. $\tau_{1}$ histograms for fluorescein-conjugated GNR phantoms with different linkers: (a) $\mathrm{NH}_{2}$-PEG-SH-5 kDa; (b) $\mathrm{NH}_{2}$-PEG-SH-1 kDa; (c) 16-amino-1-hexadecanethiol; (d) 11-amino-1-undecanethiol; (e) 6-amino-1-hexanethiol; (f) MDDA. Histograms are shown for three areas indicated by the different colors. In all phantoms, Au concentration was $0.05 \mathrm{mg} / \mathrm{mL}$, and fluorescein concentration was $0.33 \mu \mathrm{M}$.

\section{Discussion and Conclusions}

The results described above establish that fluorescein-conjugated-GNRs are good multi-functional nano-probes for FLIM and DR dual-modal imaging. The DR results (see Figure 1) show a high correlation between the $\ln \left(\varrho^{2} \Gamma(\varrho)\right)$ slopes and the GNR concentration in the phantom: the higher the GNR concentration, the greater the slope, which indicates more intense absorption. Moreover, steeper slopes are observed for the $650 \mathrm{~nm}$ light source due to the GNRs' higher absorption in this wavelength. It should be noted that, for the $650 \mathrm{~nm}$ light source, the DR was not able to provide values if the GNR concentration was too high. This happens because, in high concentration, the absorption is dominant and all of the light is absorbed for particles of this geometry. In a similar manner, despite the absorption spectrum suggesting a low absorption at $780 \mathrm{~nm}$, the correlated increase in slope with GNR concentrations is apparent even for higher concentrations with this light source. In addition, a clear difference is observed between the control phantoms that contain only free fluorescein and the corresponding fluorescein-conjugated-GNR phantoms.

The FLIM results described above clearly show that the conjugation of fluorescein to GNRs shortens its FLT significantly for all the conjugations that were examined in this experiment, both in solution and inserted in solid tissue-imitating phantoms (Figures 6 and 7). This result is consistent with known fluorophore interactions with a nearby metal $[33,35,36]$. FLIM and DR dual-modal imaging using fluorescein-conjugated GNRs was achieved.

However, the observed FLT shortening showed no correlation to the linker length. The near-field effects of metallic nanoparticles should gain strength with decreasing distance, meaning that as a fluorophore gets closer to a particle it should exhibit a shorter FLT $[30,33]$. In the current experiment, the linkers separating the fluorescein and GNRs were chosen to vary in length from around $1 \mathrm{~nm}$ up to about $50 \mathrm{~nm}$, but the FLT values, in both solution and phantoms, did not necessarily increase with the linker length. This problem might have occurred because the chosen linkers might not be rigid enough to maintain their full length at all times.

In addition, when comparing the solution and phantom measurements, the results indicate a potential serious problem with the use of phantoms. The conjugation via the 16-amino-1-hexadecanethion (estimated length $2.5 \mathrm{~nm}$ ) and 11-amino-1-undecanethion (estimated length $1.7 \mathrm{~nm}$ ) linkers show a large discrepancy between the FLT measurements of the fluorescein-conjugated-GNRs in solution and in phantoms. This difference is also noted in the 6-amino-1-hexanthiol (estimated length $0.9 \mathrm{~nm}$ ) and MDDA to a lesser extent. Meanwhile, for the $\mathrm{NH}_{2}$-PEG-SH-5 kDa and $\mathrm{NH}_{2}$-PEG-SH-1 $\mathrm{kDa}$ (estimated length $50 \mathrm{~nm}$ and $10 \mathrm{~nm}$, respectively), the change from solution to phantom is much less pronounced (see Figures 3,5 and 6). It seems that the phantoms affect the probes and change their properties to extents that vary based on the linkers 
separating the GNRs and fluorophores, though not necessarily in correlation with the end-to-end lengths of the linkers. It is possible that in a phantom, a linker's configuration changes due to the viscosity created by the solidification of the phantom, and subsequently, differences are detected between phantoms and solutions. The $\mathrm{NH}_{2}-\mathrm{PEG}-\mathrm{SH}-5 \mathrm{kDa}$ and $\mathrm{NH}_{2}-\mathrm{PEG}-\mathrm{SH}-1 \mathrm{kDa}$ linkers are significantly longer molecules than the others so that they might fold upon themselves both in solutions and in phantoms and, therefore, the effect of their insertion into phantoms is minimized.

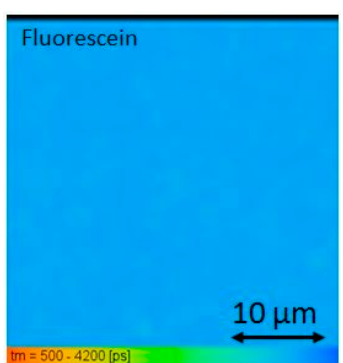

(a)

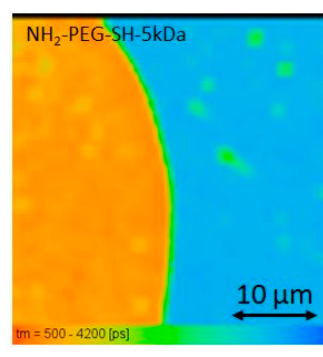

(b)

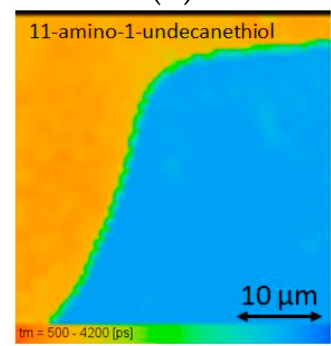

(e)

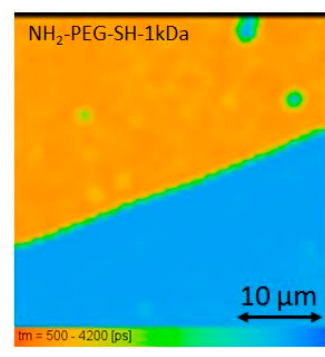

(c)

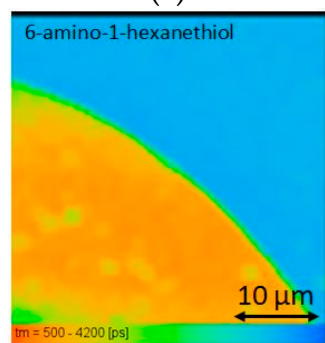

(f)

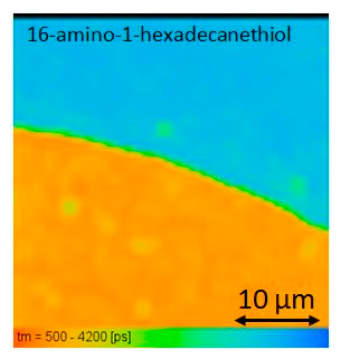

(d)

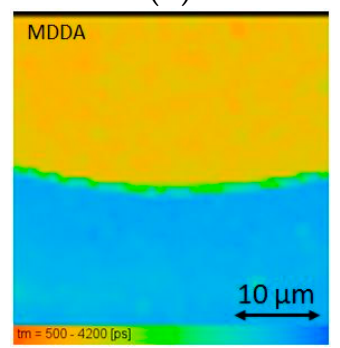

(g)

Figure 6. FLIM images of (a) free fluorescein control phantom, and the image of the interface region of base phantoms containing free fluorescein (fluorescein concentration of $330 \mathrm{nM}$ ) and phantoms containing fluorescein-conjugated-GNRs with conjugation through different likers: (b) $\mathrm{NH}_{2}$-PEG-SH-5 $\mathrm{kDa}$; (c) $\mathrm{NH}_{2}$-PEG-SH-1 kDa; (d) 16-amino-1-hexadecanethiol; (e) 11-amino-1-undecanethiol; (f) 6-amino-1-hexanethiol; (g) MDDA (Au concentration $0.05 \mathrm{mg} / \mathrm{mL}$, fluorescein concentration of $330 \mathrm{nM})$. Color indicates the average FLT in each pixel.

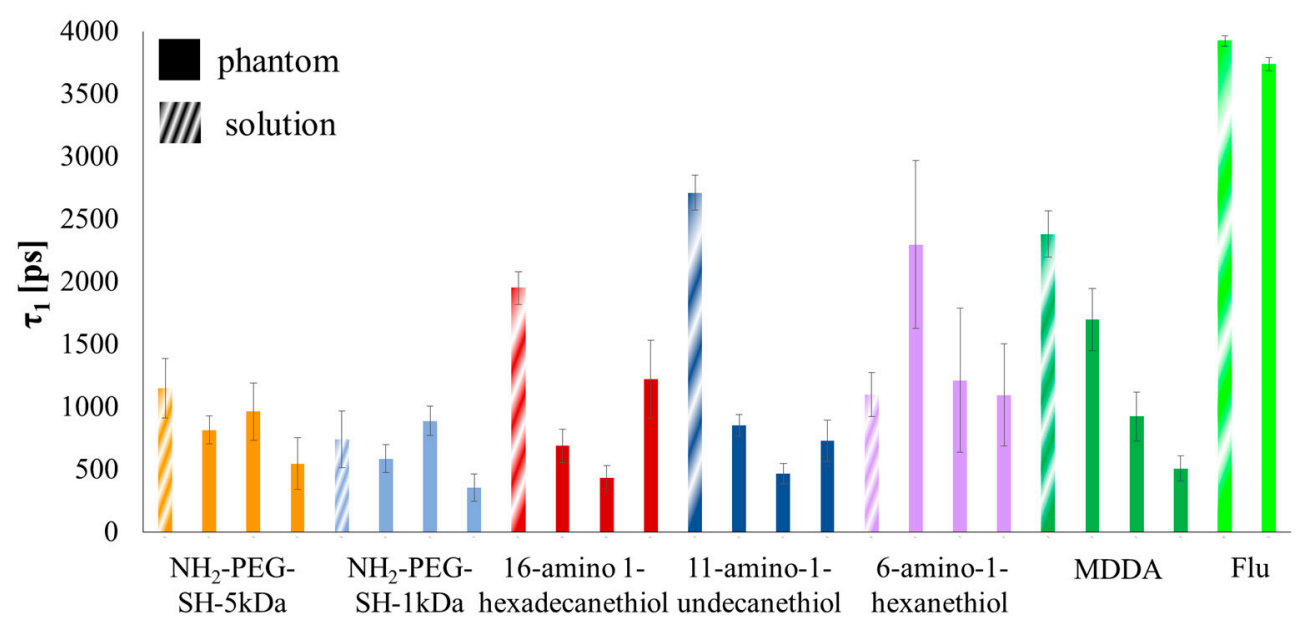

Figure 7. Bar plot of $\tau_{1}$ for fluorescein-conjugated GNRs with different linkers' solutions and phantoms (indicated by striped or solid texture respectively), where three area measurements are shown for each phantom. Free fluorescein solution and phantom FLTs are shown at the end for comparison.

Moreover, there is no clear consistency in the FLT results of different areas within the same phantoms (see Figures 5 and 6). This incongruity, as well as the observed difference in the FLT 
measurements of free fluorescein in solution and phantom (see Figure 6), leads us to assume that the solidification process of the phantoms might also affect the spatial distribution of the nano-probes, creating areas of higher and lower concentrations, which might affect the phantom results as well.

In conclusion, fluorescein-conjugated-GNRs placed in tissue-imitating phantoms pose as viable dual-imaging probes for DR and FLIM, albeit with caveats. One issue arises from the use of non-rigid linkers, which will not necessarily retain their spatial configuration. Another issue is that it is not clear that tissue-like phantoms can maintain the optical properties of contrast agents inserted into them and, therefore, the usage of phantoms as a model for measuring the behavior of inserted probes needs to be carefully examined for each probe of interest.

\section{Materials and Methods}

\subsection{GNRs Fabriction}

GNRs with an absorption peak of approximately $650 \mathrm{~nm}$ were synthesized using the seed-mediated growth method [37]. The absorption spectrum of the GNRs was verified by a spectrophotometer before and after conjugation to fluorescein (see Figure 8a), after conjugation to fluorescein the absorption spectrum becomes broader due to slight changes in the particles' geometry and the addition of another refractive index indicating the conjugation as expected. The GNRs' shape and size were verified by transmission electron microscopy (TEM) (see Figure 8b).

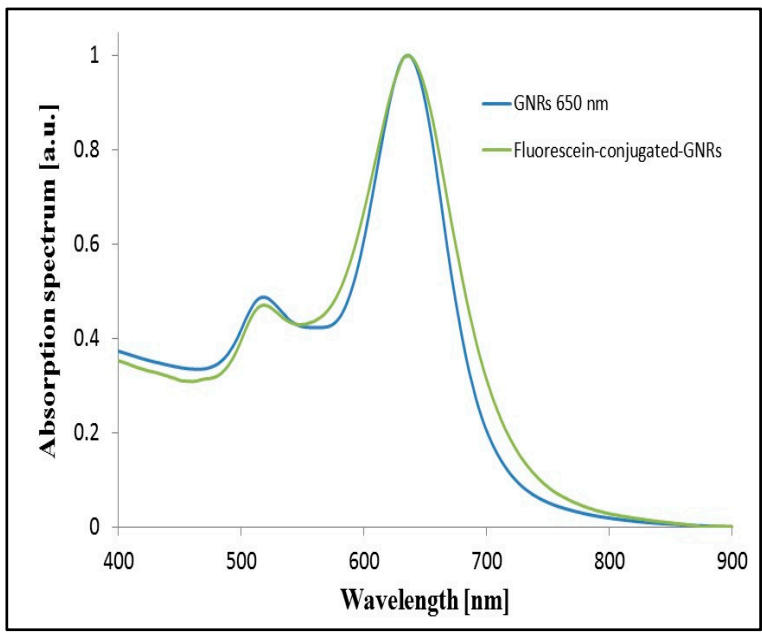

(a)

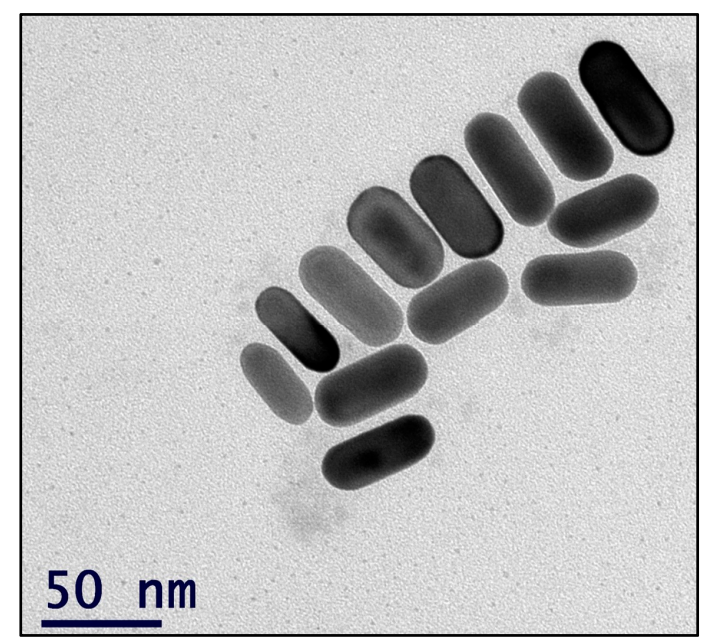

(b)

Figure 8. GNRs characteristics: (a) GNRs normalized absorption spectrum; (b) GNRs TEM image.

\subsection{Flourescein Conjugation to GNRs}

GNRs were coated with a linker mixture (the different mixtures are summarized in Table 3 and a schematic representation of their varying length is presented in Figure 9) by adding the linker mixture to the GNR solution and stirring for at least $2 \mathrm{~h}$, after which the fluorescein solution was added to create either covalent or overlap binding with the linkers. In cases of covalent binding, EDC (1-Ethyl-3-(3-dimethylaminopropyl) carbodiimide $\mathrm{HCl}$ ) and NHS (N-Hydroxysulfosuccinimide sodium salt), which are activating agents that help to form the desirable bond by creating good leaving groups, were added as well [38]. Similar binding has been done before [39]. The GNR solutions were then left to stir overnight. A schematic representation of the process is shown in Figure 10. In order to wash unattached fluorescein, the solutions were diluted with DDW and centrifuged until precipitation of the GNRs, and a clear suspension was obtained. The MDDA linker does not bind to the GNRs through a SH group but rather envelops the GNRs. 
Table 3. This table lists the different linkers' mixtures, the percentage of each linker in these mixtures and the matching fluorescein coating percentage.

\begin{tabular}{|c|c|c|c|c|c|c|}
\hline Linker A & $\begin{array}{c}\text { \% Coating } \\
\text { A }\end{array}$ & $\begin{array}{l}\text { Estimated Linker } \\
\text { Length }[\mathrm{nm}]\end{array}$ & Linker B & $\begin{array}{c}\text { \% Coating } \\
\text { B }\end{array}$ & $\begin{array}{l}\text { \% Coating } \\
\text { Fluorescein }\end{array}$ & $\begin{array}{c}\text { Binding } \\
\text { Type }\end{array}$ \\
\hline $\begin{array}{l}\text { NH2-PEG-SH-5 kDa } \\
\text { (MW } 5000 \mathrm{~g} / \mathrm{mol})\end{array}$ & $10 \%$ & 50 & $\begin{array}{l}\text { mPEG-SH-5 kDa } \\
(\mathrm{MW} 5000 \mathrm{~g} / \mathrm{mol})\end{array}$ & $90 \%$ & $10 \%$ & $\begin{array}{l}\text { Covalent } \\
\text { binding }\end{array}$ \\
\hline $\begin{array}{l}\text { NH2-PEG-SH-1 kDa } \\
\text { (MW } 5000 \mathrm{~g} / \mathrm{mol})\end{array}$ & $10 \%$ & 10 & $\begin{array}{l}\text { mPEG-SH-1 kDa } \\
(\mathrm{MW} 1000 \mathrm{~g} / \mathrm{mol})\end{array}$ & $90 \%$ & $10 \%$ & $\begin{array}{l}\text { Covalent } \\
\text { binding }\end{array}$ \\
\hline $\begin{array}{l}\text { 16-amino-1-hexadecanethiol } \\
\text { (MW } 309.98 \mathrm{~g} / \mathrm{mol} \text { ) }\end{array}$ & $10 \%$ & 2.5 & $\begin{array}{l}\text { 1-octanethiol 98.5+\% } \\
(\mathrm{MW} 146.29 \mathrm{~g} / \mathrm{mol})\end{array}$ & $90 \%$ & $10 \%$ & $\begin{array}{l}\text { Covalent } \\
\text { binding }\end{array}$ \\
\hline $\begin{array}{l}\text { 11-amino-1-undecanethiol } \\
\text { (MW 239.85 g/mol) }\end{array}$ & $10 \%$ & 1.7 & $\begin{array}{l}\text { 1-octanethiol 98.5+\% } \\
(\mathrm{MW} 146.29 \mathrm{~g} / \mathrm{mol})\end{array}$ & $90 \%$ & $10 \%$ & $\begin{array}{l}\text { Covalent } \\
\text { binding }\end{array}$ \\
\hline $\begin{array}{l}\text { 6-amino-1-hexanethiol } \\
\text { (MW 169.72 g/mol) }\end{array}$ & $10 \%$ & 0.9 & $\begin{array}{l}\text { 1-octanethiol 98.5+\% } \\
(\mathrm{MW} 146.29 \mathrm{~g} / \mathrm{mol})\end{array}$ & $90 \%$ & $10 \%$ & $\begin{array}{l}\text { Covalent } \\
\text { binding }\end{array}$ \\
\hline $\begin{array}{l}\text { 3,4-methylenedioxy- } N, N- \\
\text { dimethylamphetamine (MDDA) } \\
\text { (MW 207.26888 g/mol) }\end{array}$ & $100 \%$ & - & - & - & $10 \%$ & $\begin{array}{l}\text { Overlap } \\
\text { binding }\end{array}$ \\
\hline
\end{tabular}

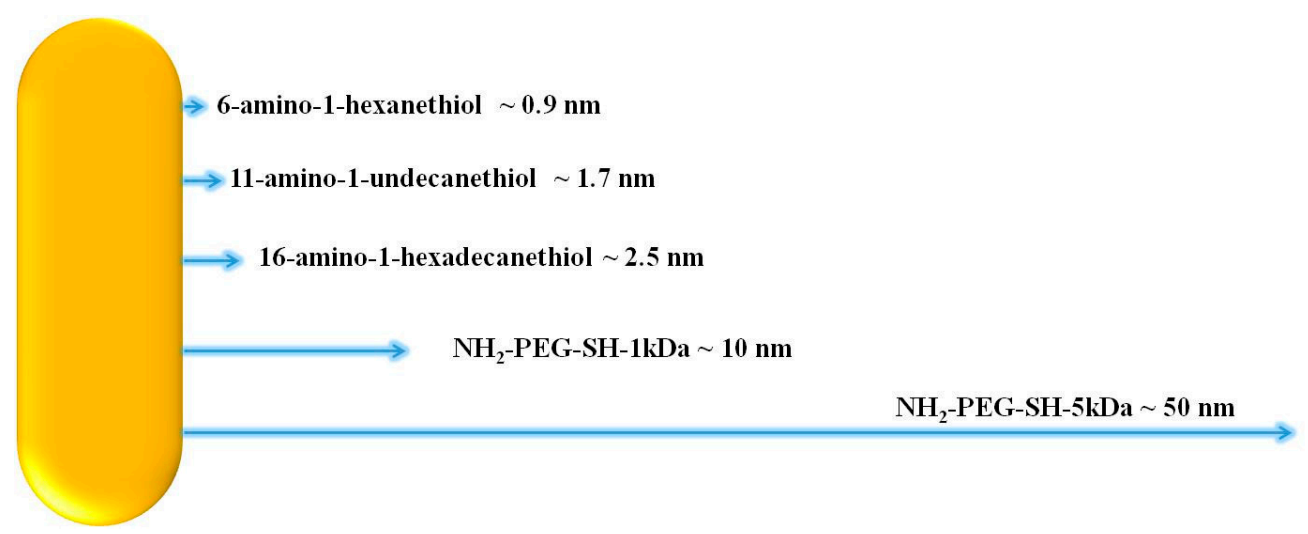

Figure 9. A schematic representation of the linkers' end-to-end length in scale relatively to each other.

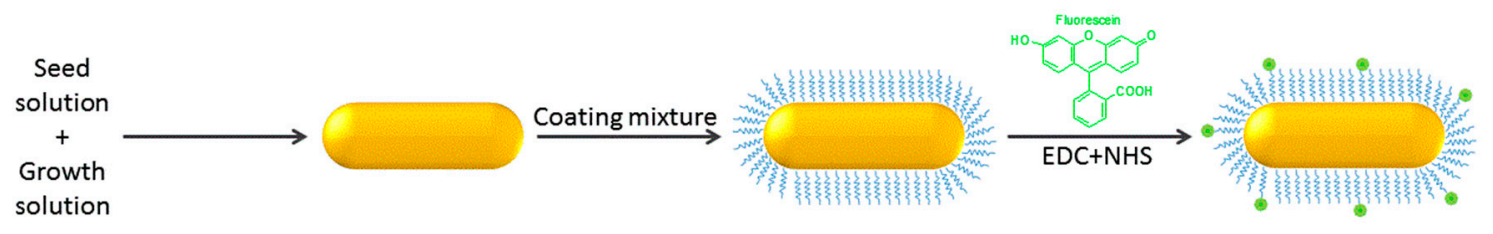

Figure 10. A schematic representation of the GNRs' fabrication and fluorescein conjugation process.

\subsection{Solid Tissue-Like Phantom Preparation}

For the DR measurements, 12 solid phantoms were prepared with fluorescein-conjugated-GNRs: six with conjugation through 11-amino-1-undecanethiol linker and six with conjugation through 6-amino-1-hexanethiol linker. The Au concentration of each set of six phantoms varied from 0.05 to $0.3 \mathrm{mg} / \mathrm{mL}$ by steps of $0.05 \mathrm{mg} / \mathrm{mL}$, and the phantoms had a final volume of $400 \mu \mathrm{L}$. In addition, control phantoms were prepared containing fluorescein with matching fluorescein concentrations ( 0.33 to $1.98 \mu \mathrm{M}$ by steps of $0.33 \mu \mathrm{M}-$ dye concentrations matching the Au concentrations) and final volume of $4 \mathrm{~mL}$.

For the FLIM measurements, a total of seven solid phantoms were prepared: one free fluorescein phantom with a total volume of $4 \mathrm{~mL}$ and final fluorescein concentration of $0.33 \mu \mathrm{M}$, and six fluorescein-conjugated-GNR phantoms with a total volume of $400 \mu \mathrm{L}$ and final Au concentration of $0.05 \mathrm{mg} / \mathrm{mL}$. 
The phantoms were prepared by mixing Intra Lipid (IL) (Lipofundin MCT/LCT 20\%, B. Braun Melsungen AG, Melsungen, Germany) as a scattering component, India ink (ink solution diluted to $0.1 \%$ ink) as an absorption component, the contrast solution of choice (free fluorescein solutions or fluorescein-conjugated-GNR solutions), double distilled water (DDW), and agarose powder (LONZA SeaKem ${ }^{\circledR}$ LE Agarose, Walkersville, MD, USA) for solidification into a gel. The materials' ratios in the final total volume are specified in Table 4. For example, the free fluorescein FLIM phantom was made of: $400 \mu \mathrm{L}$ Intralipid (IL), $120 \mu \mathrm{L}$ India ink, $132 \mu \mathrm{L}$ fluorescein solution $(10 \mu \mathrm{M}), 3.348 \mathrm{~mL}$ DDW, and $40 \mathrm{mg}$ agarose powder. Each of the fluorescein-conjugated-GNR FLIM phantoms were made of: $40 \mu \mathrm{L} \mathrm{IL}, 12 \mu \mathrm{L}$ India ink, $20 \mu \mathrm{L}$ fluorescein-conjugated-GNRs solution (Au concentration $1 \mathrm{mg} / \mathrm{mL}), 328 \mu \mathrm{L}$ DDW, and $4 \mathrm{mg}$ agarose powder.

The phantoms were prepared as follows: first, all of the ingredients but the agarose were added into a glass vial. The solution was heated and stirred. When the solution was hot agarose powder was added slowly. Once the solution was well mixed it was transferred into 12-well or 96-well tissue culture plates and cooled under vacuum (to avoid bubbles).

Table 4. Specification of the volume's ratios of the materials needed for a phantom preparation.

\begin{tabular}{ccccc}
\hline IL & $\begin{array}{c}\text { India Ink } \\
\text { (Diluted to 0.1\%) }\end{array}$ & Wanted Solution & DDW & Agarose Powder \\
\hline $\begin{array}{c}10 \% \text { of the } \\
\text { total volume }\end{array}$ & $\begin{array}{c}3 \% \text { of the total } \\
\text { volume }\end{array}$ & $\begin{array}{c}\text { X\% of the total volume } \\
\text { (depends on the wanted } \\
\text { concentration in the phantom) }\end{array}$ & $\begin{array}{c}(87-\mathrm{X}) \% \text { of the } \\
\text { total volume }\end{array}$ & $\begin{array}{c}1 \% \text { (defined as } \\
1 \mathrm{~g} \text { per } 100 \mathrm{~mL})\end{array}$ \\
\hline
\end{tabular}

\subsection{DR Measurments}

A DR system was designed and built (NEGOH-OP TECHNOLOGIES, Israel), as was previously described [40]. The setup includes two laser diodes with wavelengths of 650 and $780 \mathrm{~nm}$ as excitation sources. Irradiation is carried out using a $125 \mu \mathrm{m}$ diameter optic fiber to achieve a pencil beam illumination. A portable photodiode is used as a photo detector (a schematic of the setup is shown in Figure 11) The expected reflected light intensity as a function of the distance between the light source and the detector profile, $\Gamma(\varrho)$, is defined by:

$$
\Gamma(\rho)=\frac{c_{1}}{\rho^{2}} \exp (-\mu \rho),
$$

where $\mu=\sqrt{3 \mu_{a} \mu_{s}{ }^{\prime}}$ and is the effective attenuation coefficient, $\mu_{\mathrm{a}}$-the absorption coefficient, $\mu_{\mathrm{s}}{ }^{\prime}$-the reduced scattering coefficient, and $\varrho$ 一 the source-detector separation. This equation can be rewritten as:

$$
\ln \left(\rho^{2} \Gamma(\rho)\right)=c_{2}-\mu \rho,
$$

where $c_{2}$ is $\ln \left(c_{1}\right)$. From these equations the values of the absorption and reduced scattering coefficients can be extracted. 


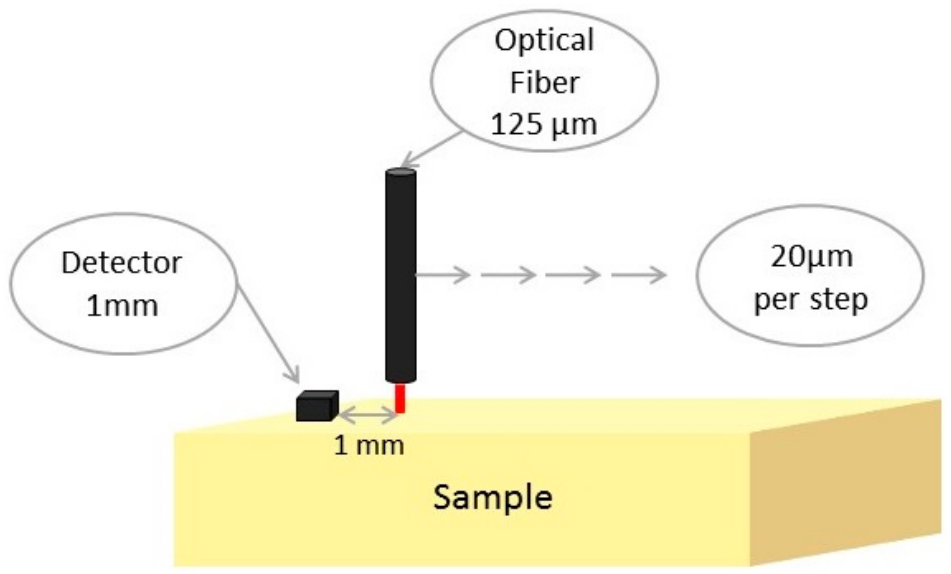

Figure 11. A schematic representation of the DR system.

\subsection{FLIM Measurments}

The FLIM system (see in Figure 12) used for FLT measurements in this article is a two-channel laser scanning confocal microscope (DCS 120, Becker and Hickl GmbH, Berlin, Germany) with two FLIM detectors. The system excites every pixel of the sample with laser pulses, at a frequency of 20, 50 , or $80 \mathrm{MHz}$. The FWHM of the excitation pulse is of the order of 10 ps -100 ps and the excitation wavelength is $470 \mathrm{~nm}$. The excitation creates fluorescence, and the system detects the FI using a time correlated single photon counting (TCSPC) card. FLTs are typically $0.1 \mathrm{~ns}-10 \mathrm{~ns}$. The fluorescence decay is fit to an exponential or sum of exponentials model by:

$$
I(t)=\sum \alpha_{i} \exp \left(-\frac{t}{\tau_{i}}\right),
$$

The amplitude-weighted FLT is calculated as defined:

$$
<\tau>=\sum \alpha_{i} \tau_{i}
$$

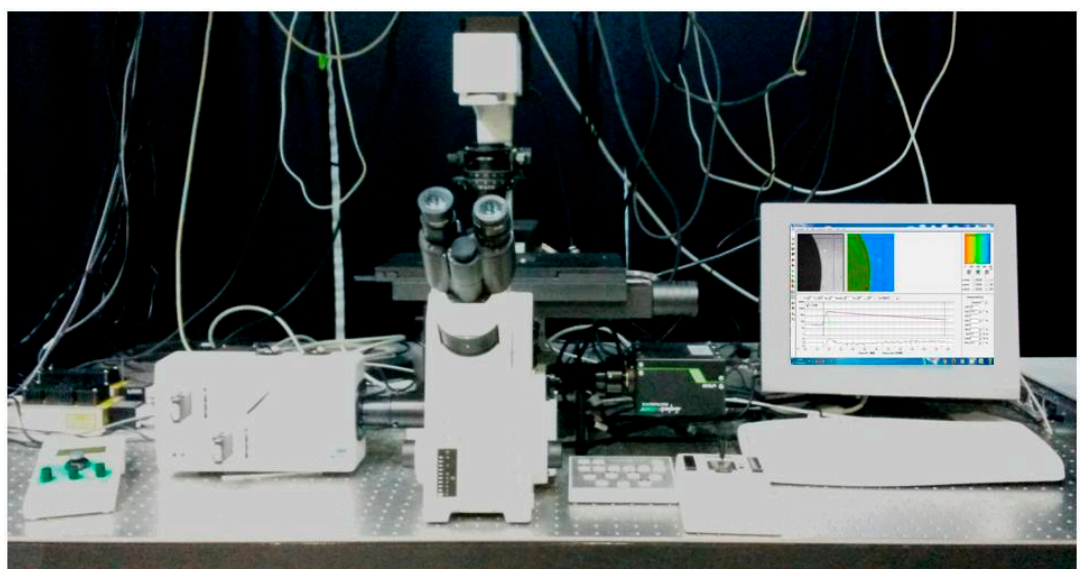

Figure 12. An image of the FLIM system.

Author Contributions: Dror Fixler and Tsviya Nayhoz conceived and designed the experiments; Tsviya Nayhoz and Eran A. Barnoy performed the experiments; Tsviya Nayhoz analyzed the data; Tsviya Nayhoz, Eran A. Barnoy and Dror Fixler wrote the paper.

Conflicts of Interest: The authors declare no conflict of interest. 


\section{References}

1. Pogue, B.W.; Patterson, M.S. Review of tissue simulating phantoms for optical spectroscopy, imaging and dosimetry. J. Biomed. Opt. 2006. [CrossRef] [PubMed]

2. Cerussi, A.E.; Warren, R.; Hill, B.; Roblyer, D.; Leproux, A.; Durkin, A.F.; O'Sullivan, T.D.; Keene, S.; Haghany, H.; Quang, T.; et al. Tissue phantoms in multicenter clinical trials for diffuse optical technologies. Biomed. Opt. Express 2012, 3, 966-971. [CrossRef] [PubMed]

3. Cubeddu, R.; Pifferi, A.; Taroni, P.; Torricelli, A.; Valentini, G. A solid tissue phantom for photon migration studies. Phys. Med. Biol. 1997, 42, 1971-1979. [CrossRef] [PubMed]

4. Mano, I.; Goshima, H.; Nambu, M.; Iio, M. New polyvinyl alcohol gel material for mri phantoms. Magn. Reson. Med. 1986, 3, 921-926. [CrossRef] [PubMed]

5. Ankri, R.; Taitelbaum, H.; Fixler, D. Reflected light intensity profile of two-layer tissues: Phantom experiments. J. Biomed. Opt. 2011. [CrossRef] [PubMed]

6. Pan, Y.; Birngruber, R.; Rosperich, J.; Engelhardt, R. Low-coherence optical tomography in turbid tissue: Theoretical analysis. Appl. Opt. 1995, 34, 6564-6574. [CrossRef] [PubMed]

7. Schmitt, J.; Lee, S.; Yung, K. An optical coherence microscope with enhanced resolving power in thick tissue. Opt. Commun. 1997, 142, 203-207. [CrossRef]

8. Bays, R.; Wagnières, G.; Robert, D.; Theumann, J.F.; Vitkin, A.; Savary, J.F.; Monnier, P.; van den Bergh, H. Three-dimensional optical phantom and its application in photodynamic therapy. Lasers Surg. Med. 1997, 21, 227-234. [CrossRef]

9. Surry, K.; Austin, H.; Fenster, A.; Peters, T. Poly(vinyl alcohol) cryogel phantoms for use in ultrasound and mr imaging. Phys. Med. Biol. 2004, 49, 5529-5546. [CrossRef] [PubMed]

10. Kennedy, B.F.; Loitsch, S.; McLaughlin, R.A.; Scolaro, L.; Rigby, P.; Sampson, D.D. Fibrin phantom for use in optical coherence tomography. J. Biomed. Opt. 2010. [CrossRef] [PubMed]

11. Leung, C.K.-S.; Cheung, C.Y.-L.; Weinreb, R.N.; Qiu, Q.; Liu, S.; Li, H.; Xu, G.; Fan, N.; Huang, L.; Pang, C.-P.; et al. Retinal nerve fiber layer imaging with spectral-domain optical coherence tomography: A variability and diagnostic performance study. Ophthalmology 2009, 116, 1257-1263. [CrossRef] [PubMed]

12. Mayhew, T.M.; Mühlfeld, C.; Vanhecke, D.; Ochs, M. A review of recent methods for efficiently quantifying immunogold and other nanoparticles using tem sections through cells, tissues and organs. Ann. Anat.-Anat. Anz. 2009, 191, 153-170. [CrossRef] [PubMed]

13. $\mathrm{Ng}$, E.-K. A review of thermography as promising non-invasive detection modality for breast tumor. Int. J. Therm. Sci. 2009, 48, 849-859. [CrossRef]

14. Cherry, S.R. Multimodality in vivo imaging systems: Twice the power or double the trouble? Annu. Rev. Biomed. Eng. 2006, 8, 35-62. [CrossRef] [PubMed]

15. Kim, J.; Piao, Y.; Hyeon, T. Multifunctional nanostructured materials for multimodal imaging, and simultaneous imaging and therapy. Chem. Soc. Rev. 2009, 38, 372-390. [CrossRef] [PubMed]

16. Lee, D.-E.; Koo, H.; Sun, I.-C.; Ryu, J.H.; Kim, K.; Kwon, I.C. Multifunctional nanoparticles for multimodal imaging and theragnosis. Chem. Soc. Rev. 2012, 41, 2656-2672. [CrossRef] [PubMed]

17. Srinivas, M.; Melero, I.; Kaempgen, E.; Figdor, C.G.; Vries, I.J.M. Cell tracking using multimodal imaging. Contrast Media Mol. Imaging 2013, 8, 432-438. [CrossRef] [PubMed]

18. Jennings, L.E.; Long, N.J. 'Two is better than one'-Probes for dual-modality molecular imaging. Chem. Commun. 2009, 3511-3524. [CrossRef] [PubMed]

19. Louie, A. Multimodality imaging probes: Design and challenges. Chem. Rev. 2010, 110, 3146-3195. [CrossRef] [PubMed]

20. Glickson, J.D.; Lund-Katz, S.; Zhou, R.; Choi, H.; Chen, I.W.; Li, H.; Corbin, I.; Popov, A.V.; Cao, W.; Song, L.; et al. Lipoprotein nanoplatform for targeted delivery of diagnostic and therapeutic agents. Mol. Imaging 2008, 7, 101-110. [PubMed]

21. Al-Jamal, W.T.; Kostarelos, K. Liposome-nanoparticle hybrids for multimodal diagnostic and therapeutic applications. Nanomedicine 2007, 2, 85-98. [CrossRef] [PubMed]

22. Kaneda, M.M.; Caruthers, S.; Lanza, G.M.; Wickline, S.A. Perfluorocarbon nanoemulsions for quantitative molecular imaging and targeted therapeutics. Ann. Biomed. Eng. 2009, 37, 1922-1933. [CrossRef] [PubMed] 
23. Hughes, M.; Caruthers, S.; Tran, T.; Marsh, J.; Wallace, K.; Cyrus, T.; Partlow, K.; Scott, M.; Lijowski, M.; Neubauer, A. Perfluorocarbon nanoparticles for molecular imaging and targeted therapeutics. Proc. IEEE 2008, 96, 397-415. [CrossRef]

24. Mulder, W.J.; Strijkers, G.J.; van Tilborg, G.A.; Cormode, D.P.; Fayad, Z.A.; Nicolay, K. Nanoparticulate assemblies of amphiphiles and diagnostically active materials for multimodality imaging. Acc. Chem. Res. 2009, 42, 904-914. [CrossRef] [PubMed]

25. Hüber, M.M.; Staubli, A.B.; Kustedjo, K.; Gray, M.H.; Shih, J.; Fraser, S.E.; Jacobs, R.E.; Meade, T.J. Fluorescently detectable magnetic resonance imaging agents. Bioconj. Chem. 1998, 9, 242-249. [CrossRef] [PubMed]

26. Uzgiris, E.E.; Sood, A.; Bove, K.; Grimmond, B.; Lee, D.; Lomnes, S. A multimodal contrast agent for preoperative MR imaging and intraoperative tumor margin delineation. Technol. Cancer Res. Treat. 2006, 5, 301-309. [CrossRef] [PubMed]

27. Fixler, D.; Nayhoz, T.; Ray, K. Diffusion reflection and fluorescence lifetime imaging microscopy study of fluorophore-conjugated gold nanoparticles or nanorods in solid phantoms. ACS Photonics 2014, 1, 900-905. [CrossRef] [PubMed]

28. Barnoy, E.; Fixler, D.; Popovtzer, R.; Nayhoz, T.; Ray, K. An ultra-sensitive dual imaging system of diffusion reflection and fluorescence lifetime imaging microscopy using metal enhanced fluorescence in solid phantoms. Nano Res. 2015, 8, 3912-3921. [CrossRef] [PubMed]

29. Ray, K.; Lakowicz, J.R. Metal-enhanced fluorescence lifetime imaging and spectroscopy on a modified SERs substrate. J. Phys. Chem. C 2013, 117, 15790-15797. [CrossRef] [PubMed]

30. Kühn, S.; Håkanson, U.; Rogobete, L.; Sandoghdar, V. Enhancement of single-molecule fluorescence using a gold nanoparticle as an optical nanoantenna. Phys. Rev. Lett. 2006, 97, 017402. [CrossRef] [PubMed]

31. Zhou, Z.; Huang, H.; Chen, Y.; Liu, F.; Huang, C.Z.; Li, N. A distance-dependent metal-enhanced fluorescence sensing platform based on molecular beacon design. Biosens. Bioelectron. 2014, 52, 367-373. [CrossRef] [PubMed]

32. Seelig, J.; Leslie, K.; Renn, A.; Kühn, S.; Jacobsen, V.; van de Corput, M.; Wyman, C.; Sandoghdar, V. Nanoparticle-induced fluorescence lifetime modification as nanoscopic ruler: Demonstration at the single molecule level. Nano Lett. 2007, 7, 685-689. [CrossRef] [PubMed]

33. Lakowicz, J.R. Radiative decay engineering 5: Metal-enhanced fluorescence and plasmon emission. Anal. Biochem. 2005, 337, 171-194. [CrossRef] [PubMed]

34. Lakowicz, J.R. Radiative decay engineering: Metal-enhanced fluorescence. In Principles of Fluorescence Spectroscopy, 3rd ed.; Springer: New York, NY, USA, 2006; pp. 841-859.

35. Lakowicz, J.R.; Ray, K.; Chowdhury, M.; Szmacinski, H.; Fu, Y.; Zhang, J.; Nowaczyk, K. Plasmon-controlled fluorescence: A new paradigm in fluorescence spectroscopy. Analyst 2008, 133, 1308-1346. [CrossRef] [PubMed]

36. Lakowicz, J.R. Introduction to fluorescence. In Principles of Fluorescence Spectroscopy, 3rd ed.; Springer: New York, NY, USA, 2006; pp. 1-24.

37. Nikoobakht, B.; El-Sayed, M.A. Preparation and growth mechanism of gold nanorods (NRS) using seed-mediated growth method. Chem. Mater. 2003, 15, 1957-1962. [CrossRef]

38. Thermo Fisher Scientific. Available online: http://www.Piercenet.Com/product/nhs-sulfo-nhs (accessed on 19 September 2016).

39. Shilo, M.; Motiei, M.; Hana, P.; Popovtzer, R. Transport of nanoparticles through the blood-brain barrier for imaging and therapeutic applications. Nanoscale 2014, 6, 2146-2152. [CrossRef] [PubMed]

40. Ankri, R.; Duadi, H.; Motiei, M.; Fixler, D. In-vivo tumor detection using diffusion reflection measurements of targeted gold nanorods-A quantitative study. J. Biophotonics 2012, 5, 263-273. [CrossRef] [PubMed]

(C) 2016 by the authors; licensee MDPI, Basel, Switzerland. This article is an open access article distributed under the terms and conditions of the Creative Commons Attribution (CC-BY) license (http://creativecommons.org/licenses/by/4.0/). 